\title{
PERFORMANCE BASED SEISMIC ANALYSIS OF RC BUILDING CONSIDERING THE EFFECT OF DUAL SYSTEMS
}

\author{
Md Zibran Pawaar', Khalid Nayaz Khan ${ }^{2}$, Syed Ahamed Raza ${ }^{3}$ \\ ${ }^{1}$ M.Tech Student of Structural Engineering, Department of Civil Engineering, Ghousia College of Engineering, \\ Ramanagaram, Karnataka, India \\ ${ }^{2}$ Associate Professor, Department of Civil Engineering, Ghousia College of Engineering, Ramanagaram, Karnataka, \\ India \\ ${ }^{3}$ Assistant Professor, Department of Civil Engineering, Ghousia College of Engineering, Ramanagaram, Karnataka, \\ India
}

\begin{abstract}
Due to the present increase in world population, people in this world tend to occupy available locations present in any zone which also include zones falling in the high seismic zone categories. The buildings to be built in these seismic zones are more susceptible to earthquakes for obvious reasons, and the buildings constructed in such zones must be analysed and designed for the unpredictable earthquakes with unpredictable magnitudes by various lateral load resisting systems such as shear walls, bracings, tubular systems, coupled shear walls and even a combination of two load resisting systems called as dual systems. Present study includes linear-static and non-linear static analysis with different shear wall arrangements on dual systems such as flat slabs and shear walls \& moment resisting frames and shear walls for different irregular plans using ETABS 9.7.4 software. Parameters such as point displacements, base shears, pushover curves are studied.
\end{abstract}

Keywords: Dual Systems, Flat slabs, Pushover analysis, Shear walls.

\section{INTRODUCTION}

Presently there has been a tremendous increase in the amount of tall storey's in modern localities and their pressing concern is on the appearance of the structure which is supposed to be tall slender. Along with these choices the structure should be taken care of performance wise. Since the structures being tall and slender are subjected to seismic and wind loads. If the structure is not stiff enough to resist the loads and vibrations caused. Therefore its important for these structures to resist lateral forces along with vertical forces. Dual systems have been recognized to resist lateral loads effectively, since it's a combination of two load resisting systems. Combination of moment resisting frames along with shear walls and flat slabs with shear walls can be used. Shear walls are vertical most commonly used structures which act like vertical cantilevers to resist the lateral loads effectively, such an element when combined does give a good performance.

\subsection{Dual Systems}

The concept behind the dual system is to resist lateral load by combining the two lateral load resisting systems. In these systems the shape of the deformation will differ from those in frames and wall systems, where effecting interlaced force occur and change the shape of shear and moment diagrams. One of the advantages of this combination is that the frames support the wall at the top and control their displacement. Beside, the wall supports the frame at the bottom and decreases their displacement.

\subsection{Objectives}

i. To compare various results such as, Base shear, Point displacements and Story drift using linear static and non-linear static analysis

ii. To know the effect of dual systems under seismic forces by linear static and non-linear static analysis.

iii. To study and compare the performance of geometrically irregular shaped structural rc building models.

\subsection{Analytical Methods}

\subsubsection{Linear Static Analysis}

In a linear static analysis displacements, strains, stresses, and reaction forces under the effect of applied loads are calculated. It calculates the effects of steady loading conditions on a structure, while ignoring inertia and damping effects, such as those caused by time-varying loads. A static analysis can, however, include steady inertia loads (such as gravity and rotational velocity), and timevarying loads that can be approximated as static equivalent loads (such as the static equivalent wind and seismic loads commonly defined in many building codes).

\subsubsection{Non-Linear Static Analysis (Pushover} Analysis)

Pushover analysis is defined as an analysis wherein a mathematical model directly incorporating the nonlinear load-deformation characteristics of individual components 
and elements of the building shall be subjected to monotonically increasing lateral loads representing inertia forces in an earthquake until a, ,target displacemente is exceeded. Target displacement is the maximum displacement (elastic plus inelastic) of the building at roof expected under selected earthquake ground motion.

\section{ANALYTICAL MODELS CONSIDERED}

\subsection{Description of Building Structure}

The buildings are modeled as a series of load resisting elements. The lateral loads to be applied on the buildings are based on the Indian standards. The study is performed for seismic zone V as per IS 1893:2002. The frames are assumed to be firmly fixed at the bottom and the soil structure interaction is neglected.

Table 1: Model data of Building

\begin{tabular}{|l|l|}
\hline Structure & SMRF \\
\hline No of Stories & G+14 \\
\hline Storey Height & $3 \mathrm{~m}$ \\
\hline Base Storey & $3.5 \mathrm{~m}$ \\
\hline Type of Soil & Medium Soil \\
\hline Seismic Zone & 5 \\
\hline Importance factor & 1 \\
\hline Material Property & M30 \\
\hline Grade of Concrete & Fe415 \\
\hline Grade of Steel & $300 \times 450 \mathrm{~mm}$ \\
\hline Member Properties & $500 \times 500 \mathrm{~mm}$ \\
\hline Beam Size & $230 \mathrm{~mm}$ \\
\hline Column Size & $150 \mathrm{~mm}$ \\
\hline Shear wall Size & $3 \mathrm{KN} / \mathrm{m}^{2}$ \\
\hline Thickness of Slab & $2.5 \mathrm{KN} / \mathrm{m}^{2}$ \\
\hline Live Load & $1 \mathrm{KN} / \mathrm{m}^{2}$ \\
\hline Live Load on Roof &
\end{tabular}

Model 1: Diaphragm discontinuity plan Modeled as Bare Frame.

Model 2: E-shape Plan Modeled as bare Frame.

Model 3: Diaphragm discontinuity plan modeled with flat slabs and shear walls(at corners)

Model 4: E-shape plan modeled with flat slabs and shear walls (at re-entrant corners).

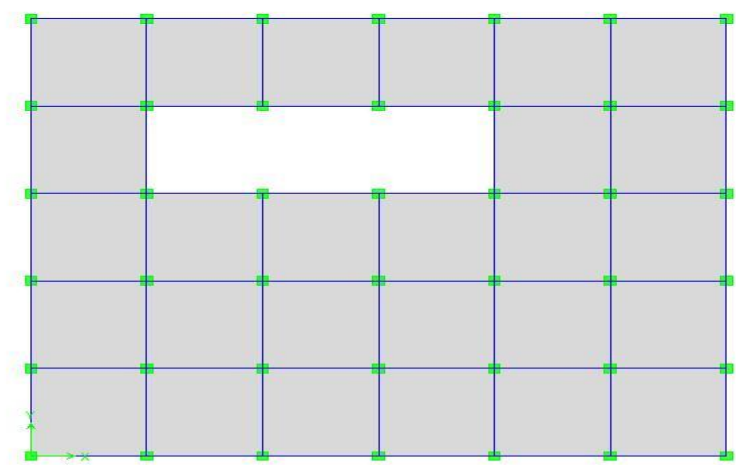

Fig 1: Model 1

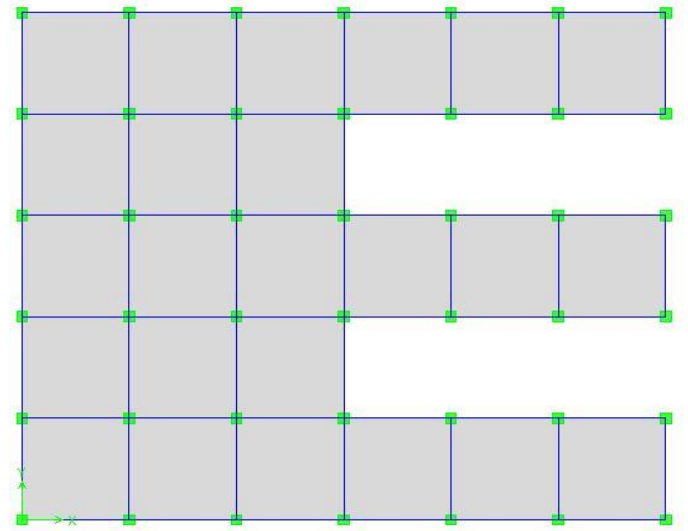

Fig 2 Model 2

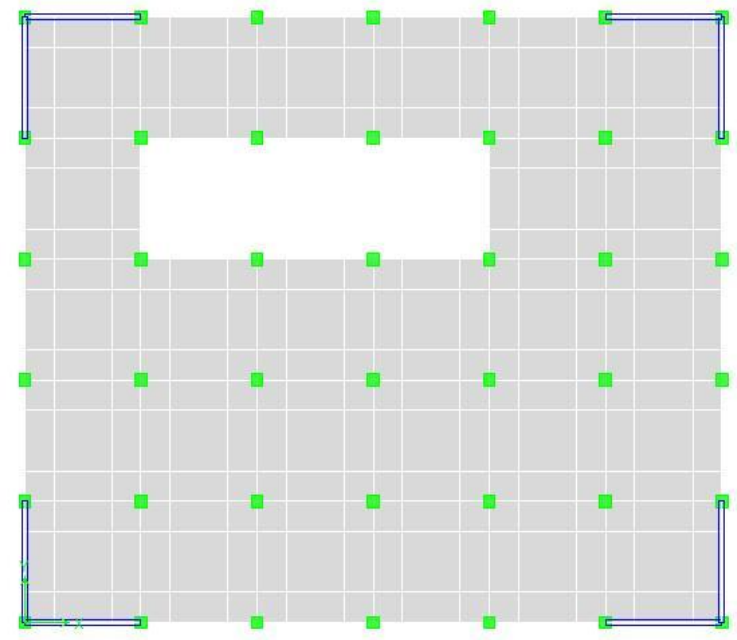

Fig 3 Model 3

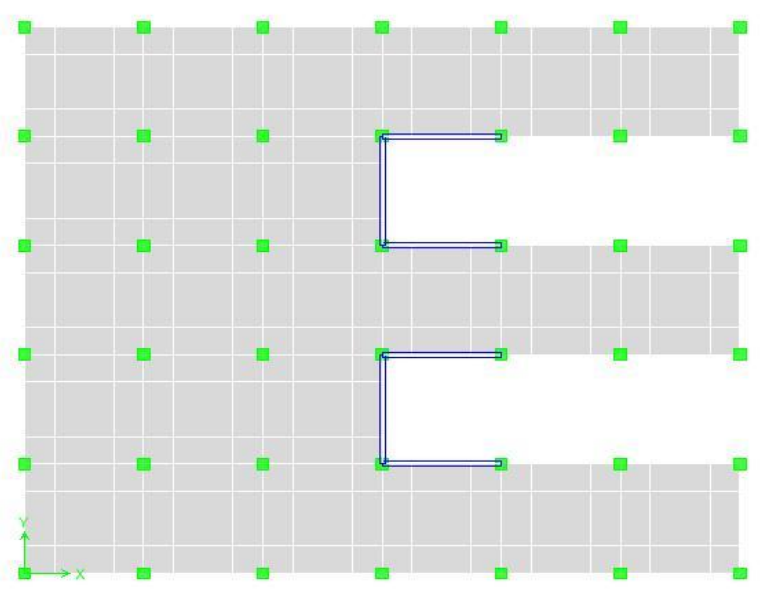

Fig 4 Model 4 


\section{RESULTS AND DISCUSSIONS}

In this paper the results of all the building models are presented. Analysis were carried out using ETABS and different parameters studied such as Base shear, Point displacement, and Pier Forces, the tables and figures are shown below.

\subsection{Base Shears}

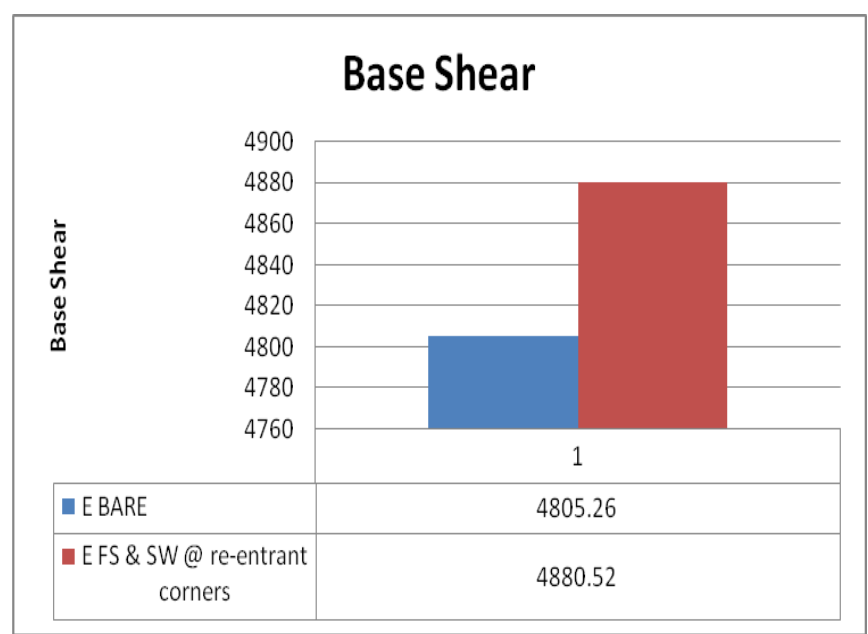

Fig 5 Base Shears For E Model.

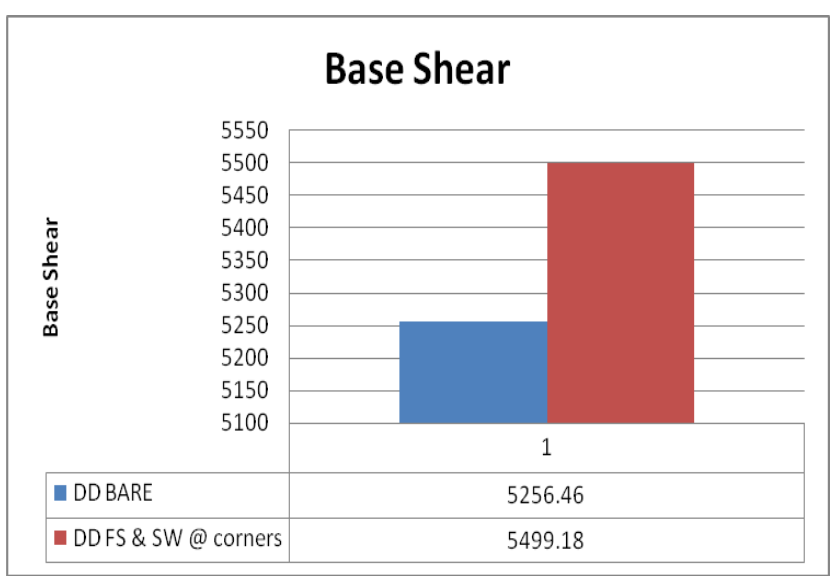

Fig 6 Base Shears for Diaphragm Discontinuity Model.

\subsection{Storey Drifts}

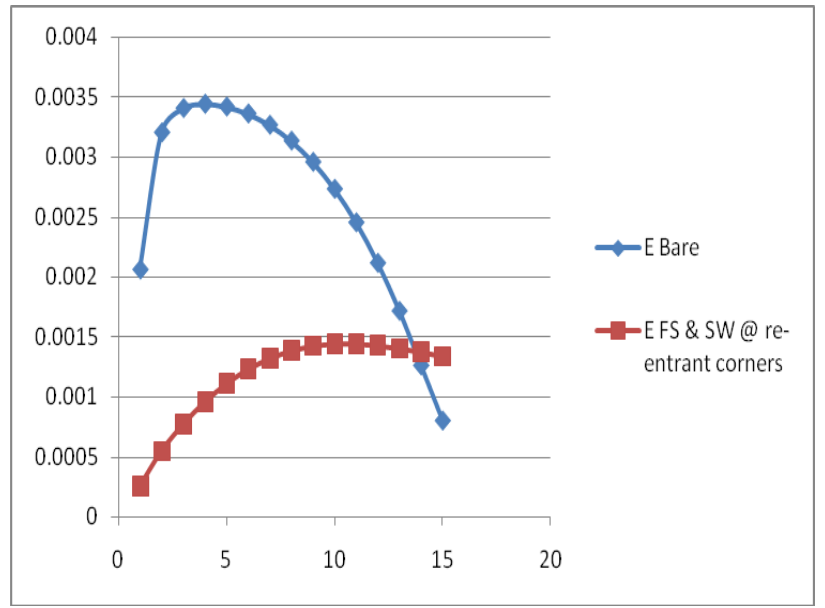

Fig 7 Storey Drifts For E Model.

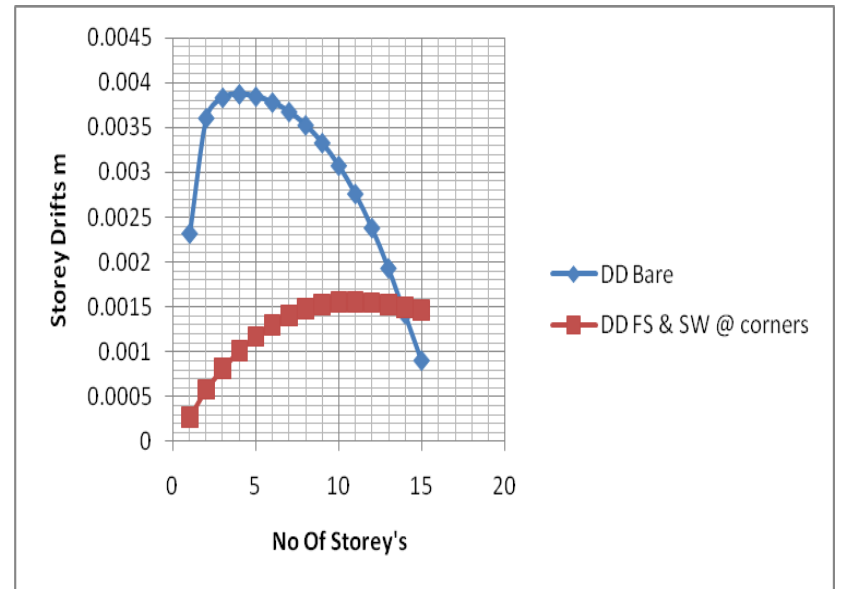

Fig 8 Storey drifts for Diaphragm Discontinuity Model

\subsection{Point Displacements}

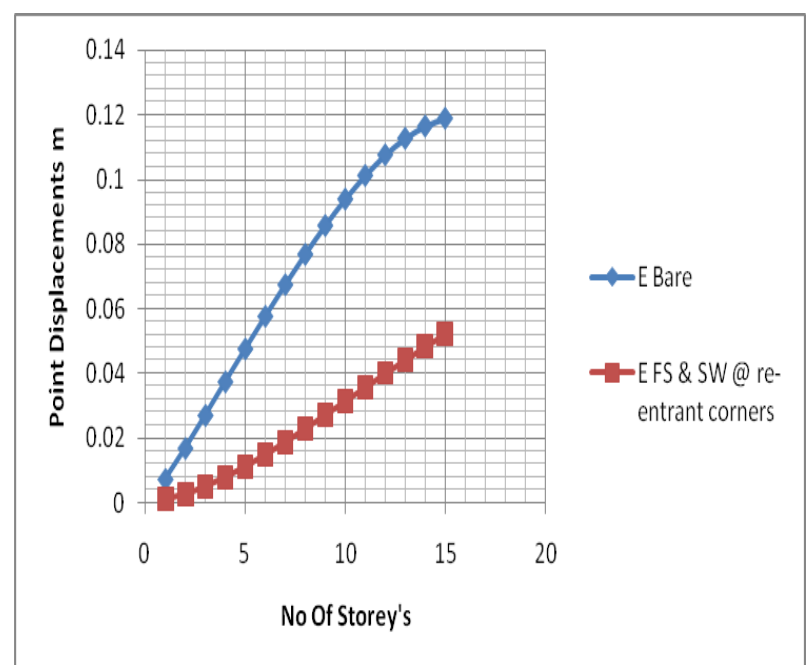

Fig 9 Point displacements For E Model

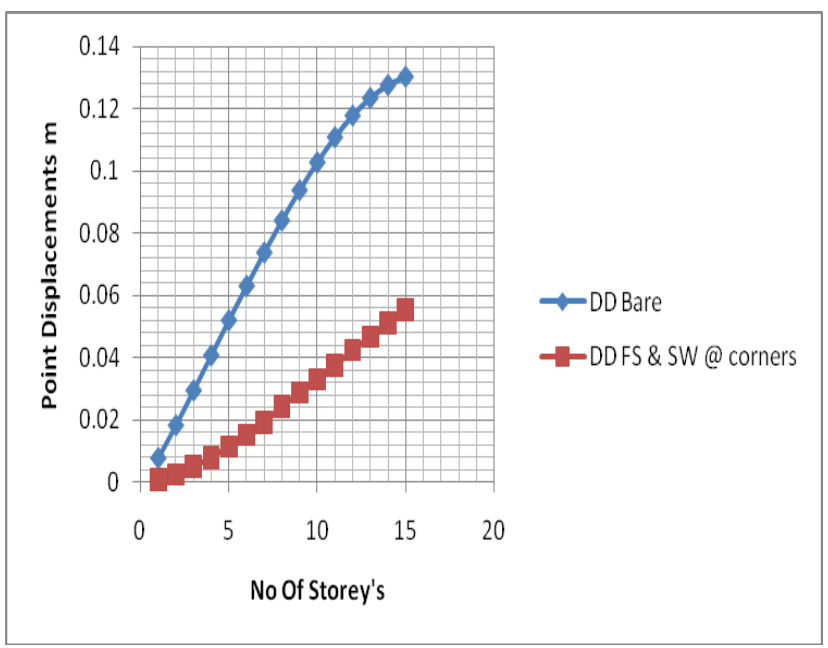

Fig 10 Point Displacements For Diaphragm Discontinuity 


\subsection{Pushover Curves (Diaphragm Discontinuity}

\section{Models)}

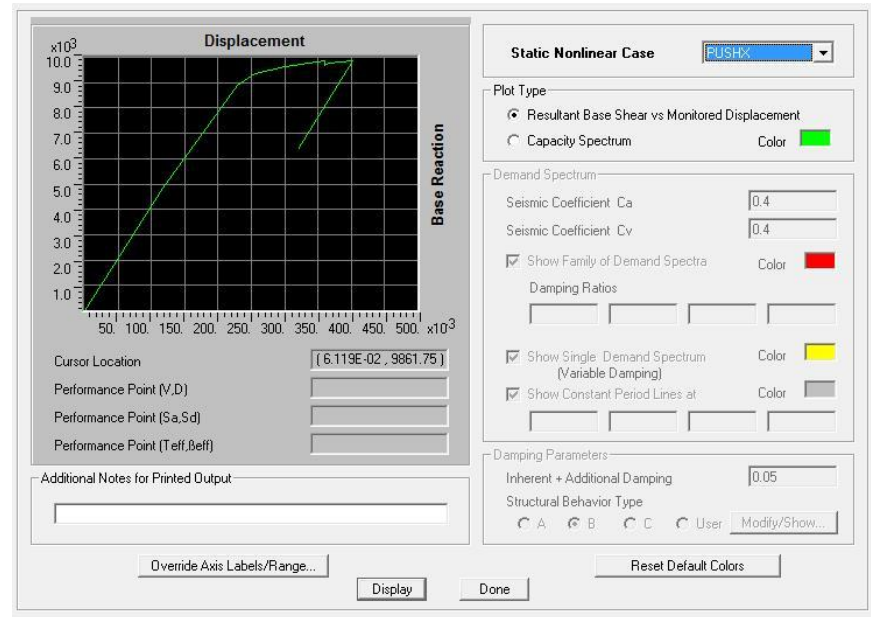

Fig 11 Pushover Curve For DD Bare Frame in X Dir.

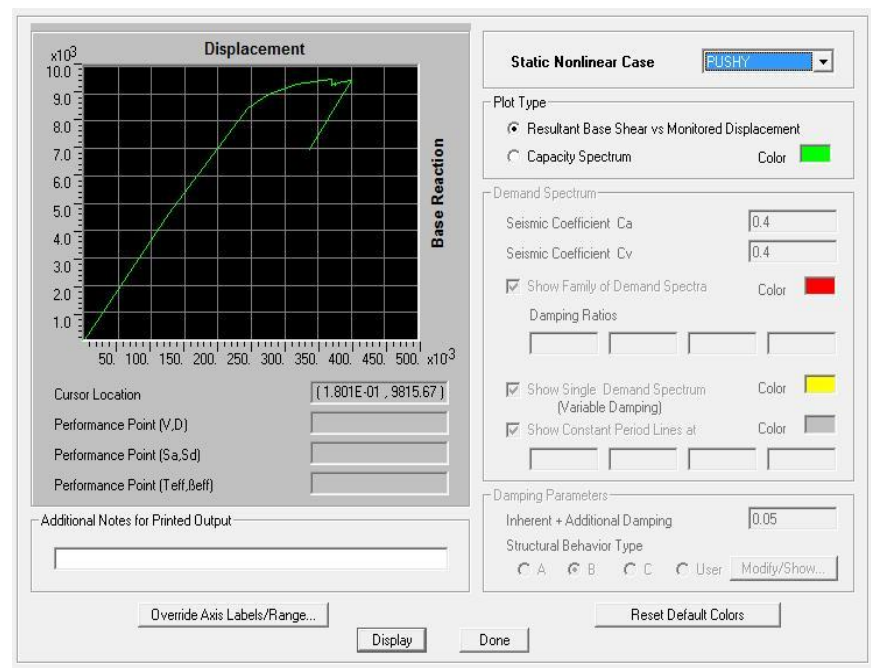

Fig 12 Pushover Curve For DD Bare Frame in Y Dir.

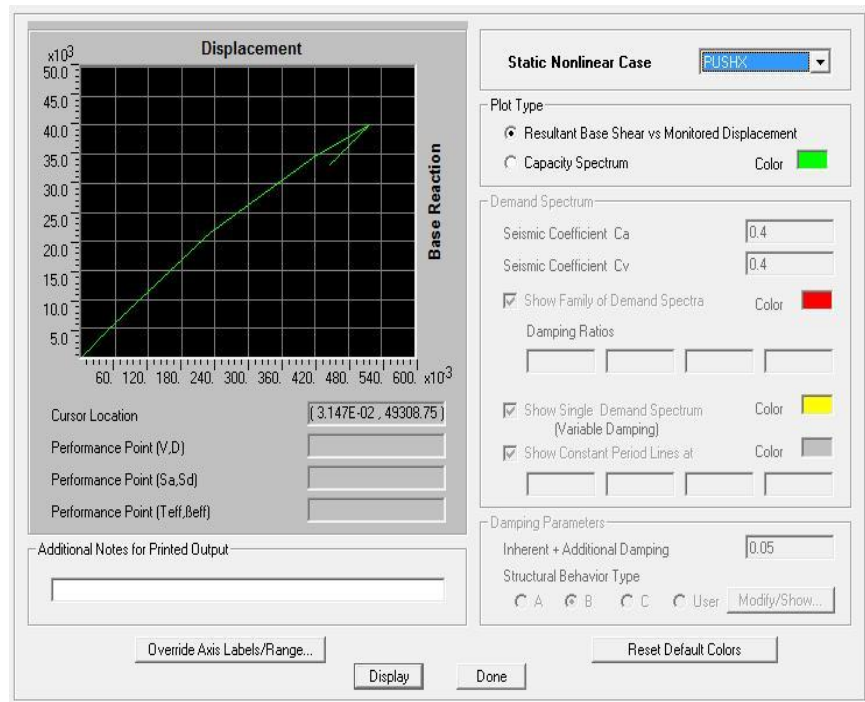

Fig 13 Pushover Curve For DD FS \& SW @ Corners in X Dir.



Fig 14 Pushover Curve For DD FS \& SW @ Corners in Y Dir.

\subsection{Pushover Curves (E Shaped Models)}



Fig 15 Pushover Curve For "E" Bare Frame in X Dir.

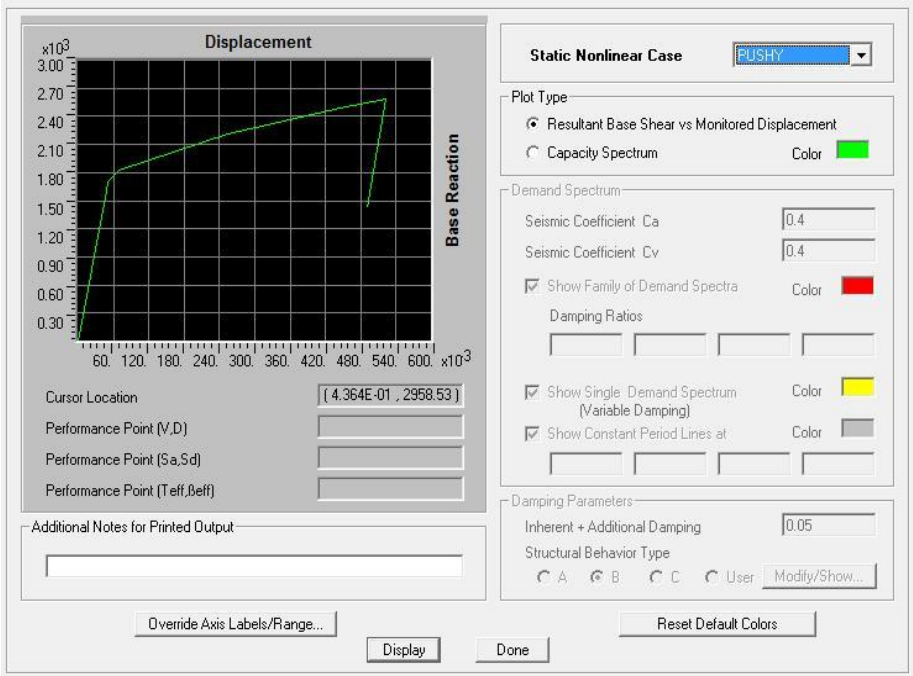

Fig 16 Pushover Curve For "E" Bare Frame in Y Dir. 


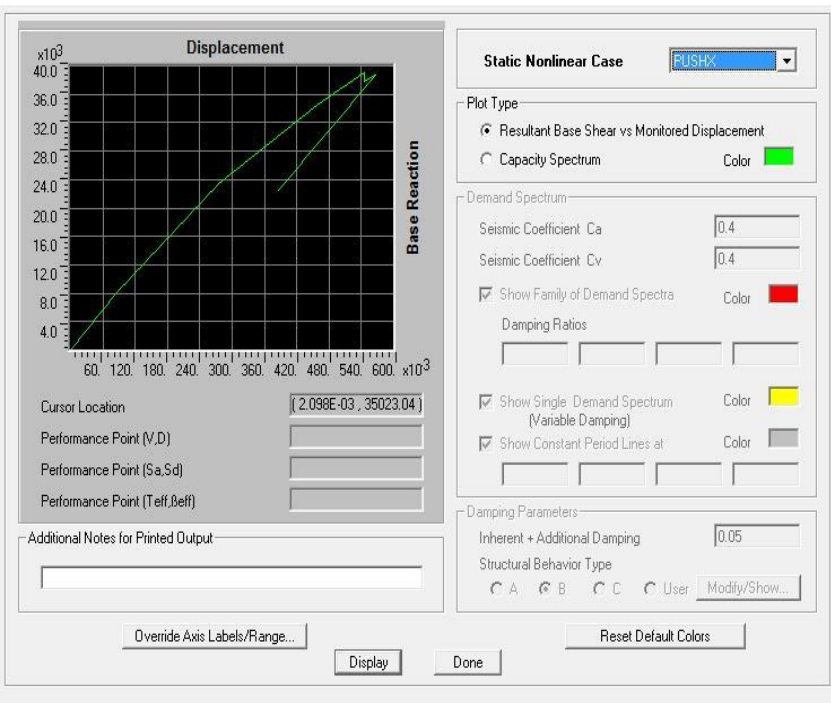

Fig 17 Pushover Curve For "E" FS \& SW @ re-entrant corners in X Dir



Fig 18 Pushover Curve For "E" FS \& SW @ re-entrant corners in Y Dir.

\section{CONCLUSION}

- $\quad$ The above results show that the storey drifts are found to be minimum in flat slabs and shear wall combination in both $\mathrm{E}$ and diaphragm discontinuity models.

- $\quad$ Storey drift at al the levels in model E and diaphragm discontinuity model are almost same but model $\mathrm{E}$ has slightly less storey drift compared to diaphragm discontinuity model.

- When the point displacement are considered for these four models, model $\mathrm{E}$ with combination of shear wall at re-entrant corners and flat slabs are found to give better results.

- $\quad$ The base shear for dual system model for diaphragm discontinuity is more than that of $\mathrm{E}$ model making $\mathrm{E}$ model dual system better compared to diaphragm discontinuity model.

- Non-linear curves both in longitudnal and transverse direction.

\section{REFERENCES}

[1] Gayathri.H, Dr.H.Eramma, C.M.RaviKumar, Madhukaran, 2014,"A Comparative Study On Seismic Performance Evaluation Of Irregular Buildings With Moment Resisting Frames And Dual Systems"

[2] Navyashree K, Sahana T.S, 2014, "Use Of Flat Slabs In Multi-Storey Commercial Building Situated In High Seismic Zone".

[3] Prof. K S Sable, Er. V A Ghodechor, Prof. S B Kandekar, " Comparative Study of Seismic Behavior of Multistory Flat Slab and Conventional Reinforced Concrete Framed Structures"

[4] Nabin Raj .C, S.Elavenil, 2012, Presented a paper on " Analytical Study on Seismic Performance of Hybrid (DUAL) Structural System Subjected To Earthquake"

[5] IS: 1893-2002 (part 1), "Indian Standard Criteria for Earthquake Resistant Design of Structures", fifth revision, Bureau of Indian Standards, New Delhi.

\section{BIOGRAPHIES}



M.Tech Student of Structural Engineering, Department of Civil Engineering, Ghousia College of Engineering, Ramanagaram, Karnataka, India



Associate Professor, Department of Civil Engineering, Ghousia College of Engineering, Ramanagaram, Karnataka, India

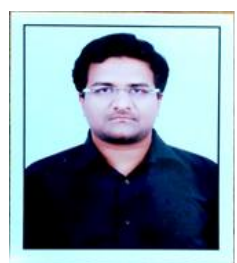

Assistant Professor, Department of Civil Engineering, Ghousia College of Engineering, Ramanagaram, Karnataka, India 